\title{
AVALIAÇÃO DA UTILIZAÇÃO DE BAGAÇO DE SORGO SACARINO TRATADO EM REATOR DE ABERTURA DE FIBRA LIGNOCELULÓSICA COMO SUBSTRATO PARA PRODUÇÃO DE ETANOL
}

\author{
E. F. Q. SANTOS ${ }^{1}$, J. FISCHER ${ }^{1}$, M. C. NERY ${ }^{1}$, H. R. R. de AGUIAR ${ }^{1}$, U. C. FILHO ${ }^{1}$, V. L. \\ CARDOSO $^{1}$ \\ ${ }^{1}$ Universidade Federal de Uberlândia, Faculdade de Engenharia Química \\ E-mail para contato: emanoela.ufu@gmail.com
}

RESUMO - O objetivo deste trabalho foi projetar e testar a eficiência de um reator para prétratamento de fibras lignocelulósicas a serem utilizadas na produção de etanol de segunda geração. Para o teste do reator fermentou-se a biomassa pré-tratada, analisando como variável resposta, o etanol. A utilização da pressão de $6 \mathrm{kgf} / \mathrm{cm}^{2}$ e temperatura de $160^{\circ} \mathrm{C}$ por 10 minutos no reator construído para abertura de fibra apresentou melhores resultados de produção de etanol em relação as condições de $4 \mathrm{kgf} / \mathrm{cm}^{2}$ e $148^{\circ} \mathrm{C}$ e $8 \mathrm{kgf} / \mathrm{cm}^{2}$ e $170{ }^{\circ} \mathrm{C}$ no mesmo reator.

\section{INTRODUÇÃO}

A produção de etanol de primeira geração consiste na obtenção do biocombustível por meio do processo de fermentação de açúcares diretamente fermentescíveis presentes no colmo da planta, utilizando fundamentalmente enzimas responsáveis pela hidrólise da sacarose segundo os trabalhos de (NAIKet al., 2010). Já na tecnologia de produção de etanol de segunda geração, a matéria prima utilizada para produção do álcool é a biomassa vegetal, a qual tem seus polímeros de parede celular transformados em açúcares simples (pré-tratamento e sacarificação) e convertidos em etanol por meio da fermentação RUBIN (2008). Diante do grande potencial do sorgo sacarino como cultura energética, é de grande importância a caracterização agronômica e industrial dos cultivares visando estimar o potencial desta cultura para produção de biocombustíveis de primeira e segunda geração.

Desse modo, de forma alternativa à cana-de-açúcar, o sorgo sacarino tem se destacado como uma cultura de elevado potencial para produção de biocombustível. O sorgo apresenta ciclo curto (quatro meses), plantio e colheita totalmente mecanizáveis, colmos com açúcares fermentescíveis e seu bagaço pode ser utilizado para forragem, cogeração de eletricidade e produção de etanol de segunda geração (PARRELLA et al., 2010). Além disso, o sorgo possui uma baixa demanda por água, característica importante no atual período de incertezas climáticas.

O objetivo do trabalho foi projetar e testar a eficiência de um reator para pré-tratamento de fibras lignocelulósicas a serem utilizadas na produção de etanol de segunda geração. Para constatar a eficácia do reator para esse fim, fermentou-se a biomassa tratada no mesmo analisando como variável resposta a produtividade do etanol, em comparação ao obtido pela fermentação do 


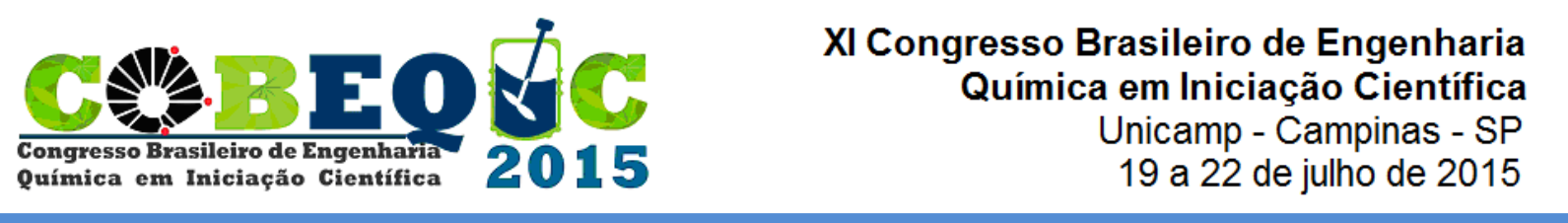

bagaço tratado pelo Centro de Tecnologia Canavieira (CTC) em condições otimizadas.

Esse reator opera a uma pressão e temperatura elevadas, consistindo em um pré-tratamento para extração dos açúcares da fração hemicelulósica,para se conseguir o fácil acesso das enzimas do complexo celulásico até a celulose.

\section{MATERIAIS E MÉTODOS}

\subsection{Reator Para Pré-Tratamento de Materiais Lignocelulósicos}

O pré-tratamento do bagaço de sorgo, em escala de bancada foi realizado noreator de aço inox $304(18 \% \mathrm{Cr}, 8 \% \mathrm{Ni})$, com capacidade para $130 \mathrm{~mL}$, mostrado na Figura 1. O reator para abertura de fibra em questão foi projetado e construído na oficina mecânica da Faculdade de Engenharia Química da Universidade Federal de Uberlândia.

Figura 1 - Reator para abertura de fibra utilizado no pré-tratamento de materiais lignocelulósicos, em escala de bancada.

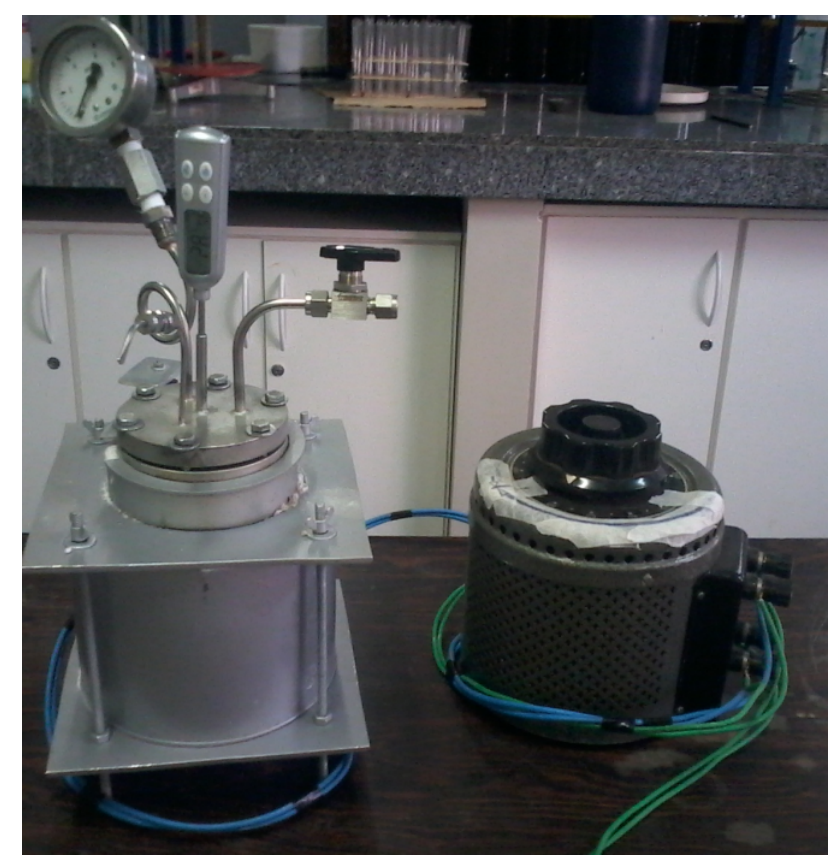

O reator possui uma resistência interna conectada a um resistor cujo controle de voltagem é feito de forma manual, variando de 0 a $240 \mathrm{~V}$. A resistência aumenta a temperatura do reator, e consequentemente a pressão, já que o sistema é conjugado. As dimensões do reator são: $60 \mathrm{~mm}$ de diâmetro, $40 \mathrm{~mm}$ de espessura e altura de $65 \mathrm{~mm}$.A pressão máxima suportada pelo reator é de $21 \mathrm{kgf} / \mathrm{cm}^{2}$ segundo os trabalhos de NORTON (2004).

\subsection{O Pré-Tratamento de Bagaço de Sorgo}


Para a etapa de pré-tratamento aproximadamente $50 \mathrm{~g}$ de bagaço moído e peneirado através de malha 100 (0,149 milímetros) foi colocada no reator pressurizado inoxidável de $300 \mathrm{ml}$ rodeado por aquecedores de cerâmica retráteis e os pré-tratamentos foram realizados fixando-se o tempo de pré-tratamento das fibras no reator em 10 minutos, e utilizando-se três pressões diferentes:4, 6 e $8 \mathrm{kgf} / \mathrm{cm}^{2}$ para abertura das fibras lignocelulósicas.

\subsection{Teste da Eficácia do Reator Para Abertura de Fibras Lignocelulósicas}

Após submeter a biomassa à etapa de pré-tratamento a alta pressão e temperatura, foram realizados alguns ensaios preliminares, consistindo na produção de um complexo enzimático gerado a partir do fungo Aspergillusniger e na sequência a obtenção de bioetanol, através da fermentação em estado sólido e em seguida, fermentação submersa FISCHER (2013).

A fermentação no estado sólido (FES) é um processo de cultura de micro-organismos realizado na superfície ou interior de partículas em matriz sólida (substrato ou material inerte) que pode ter sua composição modificada pela adição de conteúdo líquido destinado a complementar a concentração de nutrientes necessários ou mesmo manter o nível de atividade de água adequado para o crescimento e metabolismo das células DEL BIANCHI et al., (2001).

A fermentação alcoólica é realizada com os complexos enzimáticos produzidos por FES, visando avaliar a produção de etanol. É realizada em reator batelada sobre mesa agitada, com volume total de $250 \mathrm{~mL}$ e reacional de $100 \mathrm{~mL}$. As condições adotadas para a fermentação alcoólica foram as mesmas da fermentação com caldo de cana-de-açúcar, temperatura de $35 \pm$ $1^{\circ} \mathrm{C}, \mathrm{pH}$ de 4,5 , concentração de inóculo (SaccharomycescerevisiaeY904) de 30g/L. O tempo de fermentação foi de $48 \mathrm{~h}$.

Micro-organismo e biomassa celulósica: Aspergillus niger selecionado de Cerrado (região savana tropical do Brasil) foi usado para a produção de complexos de enzima bruta e fermentações alcóolicas foram realizadas utilizando Saccharomyces cerevisiae Y904. As biomassas celulósicas utilizadas foram bagaço de sorgo sacarino (Sorghum bicolor), cedido pela Embrapa (Empresa Brasileira de pesquisa Agropecuária)e bagaço de cana (ensaio comparativo) explodido a baixa severidade cedido pelo CTC (Centro de Tecnologia Canavieira).

As fermentações e produção de enzima bruta: As fermentações de estado sólido para produzir o complexo de enzima foram realizadas durante $72 \mathrm{~h}$ a $30 \pm 1^{\circ} \mathrm{C}$ em um Erlenmeyer de $250 \mathrm{ml}$ contendo 107-108 células / $\mathrm{g}$ de fungos, $40 \mathrm{~g}$ de sólido médio com $24 \mathrm{~g}$ de farelo de arroz e $16 \mathrm{~g}$ de bagaço explodiu sorgo doce (severidade 2.8). O etanol foi produzido por hidrólise simultânea e fermentação em um Erlenmeyer de $250 \mathrm{~mL}\left(48 \mathrm{~h}, 150 \mathrm{rpm}, 35^{\circ} \mathrm{C}\right)$ contendo 100 $\mathrm{mL}$ de caldo de composto de complexo de enzima em bruto extraído a partir da fermentação em estado sólido com Tween 80 (1\%) e 21 g de bagaço de sorgo sacarino explodido no reator.

Metodologia analítica: Etanol e açúcares totais foram quantificados por cromatografia líquida de alta eficiência (HPLC) usando um instrumento Shimadzu LC-20A com uma coluna proeminência SUPELCOGEL Ca, água desionizada como fase móvel, a um caudal de 0,5 mL / min, um $80^{\circ} \mathrm{C}$ temperatura do forno e um volume de injecção de $20 \mathrm{ul}$, em que as substâncias foram detectadas por índice de refracção. 


\section{RESULTADOS E DISCUSSÃO}

O Gráfico 1 mostra as concentrações finais de etanol produzido na fermentação de sorgo sacarino tratado em três condições diferentes $\left(4,6\right.$ e $\left.8 \mathrm{kgf} / \mathrm{cm}^{2}\right)$, revelando que a maior concentração final de etanol foi obtido em $6 \mathrm{kgf} / \mathrm{cm}^{2}$.

Gráfico 1 - Etanol produzido (g/L) em função da pressão de pré-tratamento do reator de abertura de fibra.

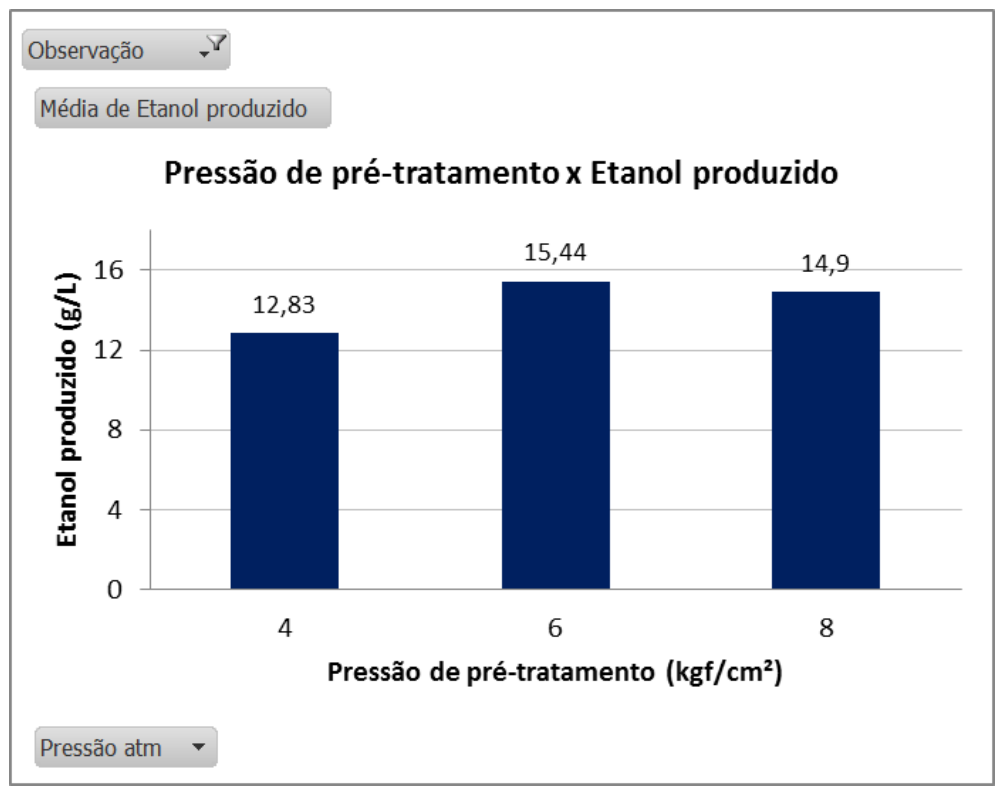

Com base nos melhores resultados de concentração de etanol $(15,44 \mathrm{~g} / \mathrm{L})$ as condições utilizadas no tratamento $\left(6 \mathrm{kgf} / \mathrm{cm}^{2}, 160^{\circ} \mathrm{C}, 10 \mathrm{~min}\right)$ foi selecionado para experimentos futuros.Condições ótimas de pré-tratamento são encontradas na literatura para o bagaço de cana, mas poucas informações estão disponíveis para bagaço de sorgo sacarino.

Um ensaio comparativo utilizando bagaço de cana (CTC) explodido a baixa severidade, FISCHER (2013) mostra que quando submetido ao mesmo processo fermentativo, o sorgo sacarinopara a produção de etanol utilizando complexos enzimáticos brutos produzidos por A. niger é promissor em termos de comparação com outros estudos utilizando enzimas comerciais e complexos enzimáticos brutos.

Não é possível variar a temperatura fixando as outras variáveis, visto que temperatura e pressão são dependentes, pois quando a resistência interna é acionada, eleva a temperatura, o que implica na formação de vapor dentro do reator e consequente elevação da pressão.

\section{CONCLUSÃO}

A utilização da pressão de $6 \mathrm{kgf} / \mathrm{cm}^{2}$ e temperatura de $160^{\circ} \mathrm{C}$ por 10 minutos no reator 


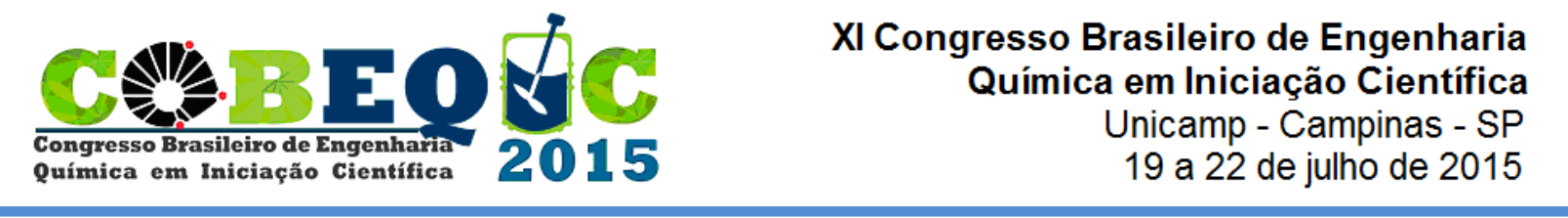

construído para abertura de fibra apresentou melhores resultados de produção de etanol em relação as condições de $4 \mathrm{kgf} / \mathrm{cm}^{2}$ e $148^{\circ} \mathrm{C}$ e $8 \mathrm{kgf} / \mathrm{cm}^{2}$ e $170{ }^{\circ} \mathrm{C}$ no mesmo reator, resultando em aproximadamente $15,5 \mathrm{~g} / \mathrm{L}$ de etanol. $\mathrm{O}$ resultado foi obtido após submeter biomassa tratada no reator a um processo fermentativo descrito no item 2.3.

Comparando-se a produtividade de etanol obtida nos testes em questão com dados da literatura, em que foram realizadas fermentações nas mesmas condições utilizando bagaço de cana-de-açúcar tratado pelo Centro de Tecnologia Canavieira segundo FISCHER (2013), constatou-se a eficácia do reator para o pré-tratamento de biomassa, visto que os resultados para a concentração de etanol obtidos nos dois casos foi aproximadamente a mesma, cerca de $15 \mathrm{~g} / \mathrm{L}$.

\section{REFERÊNCIAS}

DEL BIANCHI, V.L.; CAPALBO, D.M.F.; MORAES, I.O. Fermentação em estado sólido. In:Biotecnologia Industrial, Coord. Schmidell, W. et al., v. 2, p.247-276, 2001.

FISCHER, J. Produção de etanol pelo uso de complexo enzimático misto de Aspergillusniger e cepas selecionadas do ecossistema do Cerrado. 2013. Tese (Doutorado em Engenharia Química) - Faculdade de EngenhariaQuímica, Universidade Federal de Uberlândia, Minas Gerais.

NAIK, S. B.; GOUD, V. V.; ROUT, P. K.; DALAI, A. K. Production on first and second generation biofuels: a comprehensive review. Renewableandsustainableenergyreviews, $\mathrm{v}$. 14, p. 518-597, 2010.

NORTON, Robert L. Projeto de máquinas: uma abordagem integrada. 2. ed. Porto Alegre: Bookman, 2004.

PARRElla, R. A. C.; MENEGUCI, J. L. P.; RIBEIRO, A.; SilVA, A. R.; PARRELlA, N. L. D.; RODRIGUES, J. A.; TARDIN, F. D.; SCHAFFERT, R. E. Desempenho de cultivares de sorgo sacarino em diferentes ambientes visando à produção de etanol. Resumos expandidos. In: Congresso Nacional de Milho e Sorgo, 28, 2010. Goiânia.

RUBIN, E.M. Genomics of cellulosic biofuels. NatureReviews, vol. 454, p. 841-845, 2008. 